\title{
Relationship of EMAST and Microsatellite Instability Among Patients with Rectal Cancer
}

\author{
Bikash Devaraj • Aaron Lee • Betty L. Cabrera • Katsumi Miyai • Linda Luo • \\ Sonia Ramamoorthy $•$ Temitope Keku • Robert S. Sandler • Kathleen L. McGuire • \\ John M. Carethers
}

Received: 30 April 2010 / Accepted: 18 August 2010 /Published online: 16 September 2010

(C) The Author(s) 2010. This article is published with open access at Springerlink.com

\begin{abstract}
Background Elevated microsatellite instability at selected tetranucleotide repeats (EMAST) is a genetic signature identified in $60 \%$ of sporadic colon cancers and may be linked with heterogeneous expression of the DNA mismatch repair (MMR) protein hMSH3. Unlike microsatellite instability-high (MSI-H) in which hypermethylation of hMLH1 occurs followed by multiple susceptible gene mutations, EMAST may be associated with inflammation and subsequent relaxation of MMR function with the biological consequences not known. We evaluated the prevalence of EMAST and MSI in a populationbased cohort of rectal cancers, as EMAST has not been previously determined in rectal cancers.

Methods We analyzed 147 sporadic cases of rectal cancer using five tetranucleotide microsatellite markers and NationalCancer-Institute-recommended MSI (mononucleotide and dinucleotide) markers. EMAST and MSI determinations were made on analysis of DNA sequences of the polymerase chain reaction products and determined positive if at least two loci were found to have frame-shifted repeats upon comparison between normal and cancer samples from the same patient. We correlated EMAST data with race, gender, and tumor stage and examined the samples for lymphocyte infiltration.

Results Among this cohort of patients with rectal cancer (mean age $62.2 \pm 10.3$ years, 36\% female, $24 \%$ African American), 3/147 (2\%) showed MSI (three males, two African American) and 49/147 (33\%) demonstrated EMAST. Rectal tumors from African Americans were more likely to show EMAST than Caucasians (18/37, 49\% vs. 27/104, 26\%, $p=0.014)$ and were associated with advanced stage $(18 / 29,62 \%$ EMAST vs. $18 / 53,37 \%$, non-EMAST $p=0.02)$. There was no association between EMAST and gender. EMAST was more prevalent in rectal tumors that showed peri-tumoral infiltration compared to those without $(30 / 49,60 \%$ EMAST vs. $24 / 98,25 \%$ non-EMAST, $p=0.0001)$.

Conclusions EMAST in rectal cancer is common and MSI is rare. EMAST is associated with African-American race and may be more commonly seen with metastatic disease. The etiology and consequences of EMAST are under investigation, but its association with immune cell infiltration suggests that inflammation may play a role for its development.
\end{abstract}

$\mathrm{BD}$ and JMC designed the research. BD, AL, BLC, LL, SR performed the research. K Miyai provided pathological expertise. BD, AL and JMC analyzed data. TK and RSS provided specimens. KL McGuire provided inflammatory cell expertise. BD and JMC wrote the paper. All authors have approved the final version of this manuscript.

B. Devaraj $\cdot$ L. Luo $\cdot$ S. Ramamoorthy Department of Surgery, University of California, San Diego, CA, USA

A. Lee $\cdot$ B. L. Cabrera $\cdot$ J. M. Carethers Department of Medicine, University of California, San Diego, CA, USA
K. Miyai

Department of Pathology, University of California,

San Diego, CA, USA

S. Ramamoorthy $\cdot$ J. M. Carethers

Moores Comprehensive Cancer Center, University of California,

San Diego, CA, USA 
Keywords EMAST $\cdot$ Microsatellite instability .

Rectal cancer · DNA mismatch repair · African American

\begin{tabular}{ll}
\multicolumn{2}{l}{ Abbreviations } \\
EMAST & $\begin{array}{l}\text { Elevated microsatellite instability at selected } \\
\text { tetranucleotide repeats }\end{array}$ \\
MSI & Microsatellite instability \\
MSI-H & Microsatellite instability-high \\
MMR & Mismatch repair
\end{tabular}

\section{Introduction}

Microsatellite instability (MSI) is a hallmark of mismatch repair (MMR) dysfunction and is detected by instability at mononucleotide or dinucleotide microsatellite DNA sequences. MSI is seen in patients with Lynch syndrome and in approximately $15 \%$ of patients with sporadic colorectal cancer. The other $85 \%$ of sporadic colorectal cancers do not demonstrate this MSI pattern and have not been associated with MMR deficiency. ${ }^{1,2}$ Alterations involving specific tetranucleotide microsatellite DNA sequences, termed "elevated microsatellite alterations at selected tetranucleotide repeats," or EMAST, have not been linked to MMR dysfunction. EMAST has been previously observed in non-small-cell lung, ${ }^{3,4}$ skin, ${ }^{5}$ ovarian, ${ }^{6}$ and bladder cancers. ${ }^{5,7}$ The etiology for EMAST is not known, but EMAST has been used as a biomarker for some of these tumors.

Most recently, EMAST has been shown to have a prevalence of $\sim 60 \%$ among a cohort of sporadic colon cancers. ${ }^{8}$ Although the underlying mechanism behind EMAST remains unknown, the authors suggests that MSH3, an MMR gene involved in repair of longer repeat sequences such as those greater than dinucleotide repeats, may be linked to EMAST due to its "heterogeneous" immunohistochemical expression in some colon cancers. ${ }^{8}$

$\overline{\text { T. Keku } \cdot \text { R. S. Sandler }}$

University of North Carolina,

Chapel Hill, NC, USA

K. L. McGuire

San Diego State University,

San Diego, CA, USA

J. M. Carethers

VA Research Service,

San Diego, CA, USA

J. M. Carethers $(\square)$

Department of Internal Medicine, University of Michigan,

3101 Taubman Center, 1500 E. Medical Center Drive,

Ann Arbor, MI 48109, USA

e-mail: jcarethe@umich.edu
This type of pattern suggests an acquired defect, as no germ line mutation in MSH3 has ever been demonstrated. ${ }^{2}$ Some MMR genes, in particular MSH6 and PMS2, can be downregulated in the setting of inflammation, ${ }^{9}$ suggesting a potential mechanism for "relaxation" of DNA MMR function. An association between inflammation and EMAST has not been previously demonstrated.

Rectal cancers have a number of differences from colon cancers, but both disease processes are often lumped together in studies as colorectal cancer. Differences include (a) its embryonic origin, (b) its gender differences in incidence, (c) its molecular profile of genes, and (d) its approach to treatment. ${ }^{10-13}$ Classic MSI prevalence has been described among cohorts ranging from $0 \%$ to $20 \%,{ }^{14-16}$ but EMAST has never been evaluated among rectal cancers.

In this study, we evaluated the prevalence of MSI and EMAST in sporadic rectal cancer. We also analyzed clinicopathological features including race, gender, and disease stage and correlated these with EMAST prevalence. We also correlated the presence of inflammatory cells histologically with EMAST as a means to assess linkage of inflammation to EMAST. We observed that sporadic rectal tumors demonstrate rare MSI but commonly demonstrate EMAST. In addition, EMAST in rectal tumors is associated with the African-American race, advanced stage, and the presence of chronic inflammation.

\section{Methods}

\section{Patient Tissue and DNA Extraction}

Formalin-fixed, paraffin-embedded tissues from 147 unselected sporadic rectal cancer patients that had linked epidemiological data were used for this study. Data included gender, race, age, and tumor stage. Corresponding normal tissue was microdissected for comparison against tumor tissue from the same patient. All tissues were obtained from the North Carolina Rectal Cancer Study cohort. The project was a population-based cohort assessing rectal cancer and epidemiological data from 33 counties in North Carolina. ${ }^{17}$

Paraffin-embedded normal and tumor tissues were cut into 5- $\mu \mathrm{m}$ sections, and microdissection was performed under microscopy. Genomic DNA was isolated using GeneReleaser (Bioventure, Inc.) and then treated with proteinase $\mathrm{K}^{18}$

\section{DNA Amplification}

Each matched pair of tumor and normal tissue was subjected to 35-40 cycles of polymerase chain reaction 
(PCR). PCR was performed in a total volume of $25 \mu \mathrm{l}$ inclusive of 10-20 ng of genomic DNA, $0.2 \mu \mathrm{mol}$ of each primer, and $20 \mu \mathrm{l}$ of PCR Supermix (Invitrogen, Inc.). PCR parameters were as follows for $35-40$ cycles: $92^{\circ} \mathrm{C}$ for $1 \mathrm{~min}, 58^{\circ} \mathrm{C}$ for $40 \mathrm{~s}$, and $72^{\circ} \mathrm{C}$ for $1 \mathrm{~min}$ for most primer sets.

Mononucleotide, Dinucleotide, and Tetranucleotide Microsatellite Analysis for Rectal Cancer Tissues

Primers for each of the tetranucleotide microsatellite loci were designed and are listed in Table 1. A total of five EMAST markers (MYCL1, D20S85, D8S321, D20S82, and D9S242) and five National Cancer Institute (NCI)recommended microsatellite markers (BAT25, BAT26, D5S346, D2S123, and D17S250) ${ }^{1}$ were used. All PCR products were sequenced at the UCSD DNA Sequencing Facility in order to determine frameshifts (or instability) at each locus. Classification of microsatellite instability was performed in accordance with previously established protocols: tumors were classified as MSI-H if two or more loci showed instability compared to normal controls, MSI-L if only one locus demonstrated instability. ${ }^{1}$ MSS tumors were classified when no instability occurred at any locus. We determined EMAST in tumors demonstrating instability at tetranucleotide loci in at least two or more of the loci studied when compared to normal controls from the same patient. Non-EMAST tumors were classified if only one or no instability in tetranucleotide loci was observed. A locus was considered unstable if there was a frameshift difference in the number of repeats between the tumor and normal samples.

\section{Inflammatory Cell Infiltrate Analysis}

Hematoxylin-eosin staining was performed on all 147 samples. Each of the samples was then analyzed by a

Table 1 Tetranucleotide microsatellite PCR primer sequences

\begin{tabular}{|c|c|}
\hline Primer & Sequence \\
\hline \multirow[t]{2}{*}{ MYCL1 } & Fwd: TGG CGA GAC TCC ATC AAA G \\
\hline & Rev: CCT TTT AAG CTG CAA CAA TTT C \\
\hline \multirow[t]{2}{*}{ D20S85 } & Fwd: GAG TAT CCA GAG AGC TAT TA \\
\hline & Rev: ATT ACA GTG TGA GAC CCT G \\
\hline \multirow[t]{2}{*}{ D8S321 } & Fwd: GAT GAA AGA ATG ATA GAT TAC AG \\
\hline & Rev: ATC TTC TCA TGC CAT ATC TGC \\
\hline \multirow[t]{2}{*}{ D20S82 } & Fwd: GCC TTG ATC ACA CCA CTA CA \\
\hline & Rev: GTG GTC ACT AAA GTT TCT GCT \\
\hline \multirow[t]{2}{*}{ D9S242 } & Fwd: GTG AGA GTT CCT TCT GGC \\
\hline & Rev: ACT CCA GTA CAA GAC TCT G \\
\hline
\end{tabular}

single board-certified clinical pathologist to ascertain the presence of inflammatory cell infiltration within or around the tumors. The pathologist was blinded to the MSI and EMAST data.

\section{Statistical Analysis}

We performed statistical analysis using the Fisher exact test between clinicopathologic statuses or degree of inflammatory cell infiltration and the MSS, MSI, and EMAST groups. All $p$ values represent two-sided statistical tests with statistical significance at $p<0.05$.

\section{Results}

EMAST Is Common and MSI Is Rare in Rectal Cancers

We utilized 147 rectal cancers that had linked epidemiological data from the North Carolina Rectal Cancer Study. ${ }^{17}$ We utilized five tetranucleotide markers that have been traditionally used to define EMAST, and we considered rectal tumors as EMAST if at least two markers demonstrated instability. Based on this definition, 49/147 (33\%) demonstrated EMAST. All EMAST tumors were MSS, as MSI was rare as described below. A representative sequence demonstrating EMAST loci instability is shown in Fig. 1 and the frequency of total positive markers is shown in Table 2. The highest frequency of MSI in EMAST tumors was demonstrated at the D20S82 locus (32/49, 65\%), followed by the D8S321 locus (30/49, 61\%). The frequency of positive markers for EMAST tumors is shown in Table 2. The data suggest that EMAST is common in rectal tumors.

Using the NCI-recommended markers for MSI, only 3/ 147 (2\%) demonstrated MSI-H. All other tumors were MSS (Table 3). Thus, in our population-based cohort of rectal cancer, MSI-H is rare.

EMAST Is Correlated with Patient Race and Tumor Stage

Among the 147 patients in this cohort, the mean age was 62 \pm 10 years (range 43-79). Sixty-two percent of the patients were male and 26\% were African American. Tumor stage data were available for 82 of the 147 patients in our cohort. Correlations between age, stage, and gender with MSI and EMAST and non-EMAST tumors are shown in Tables 3 and 4, respectively. A stage classification of local was ascribed to stages 1 and 2 while regional classification was limited to stage 3 and distant to stage 4 rectal cancers.

Rectal tumors in African Americans were more likely to demonstrate EMAST compared to those in Caucasians $(18 / 37,49 \%$ vs. $27 / 104,26 \%, p=0.014)$. EMAST tumors in 
Fig. 1 D8S321 locus instability. Comparison between the normal (b) and cancer (b) sequences from the same patient reveals a deletion of two tetranucleotide repeats
(A)

Normal: (AAAG) 11

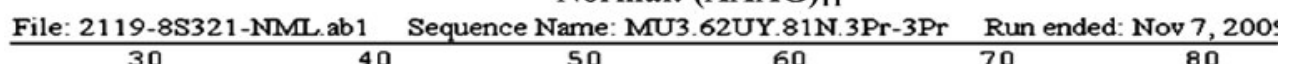

A. GA GA A GA A GAAA GAAA GAAA GAAA GAAA GAAA GAAA GAAA GAAA GAAA GAAA GAAAA. G

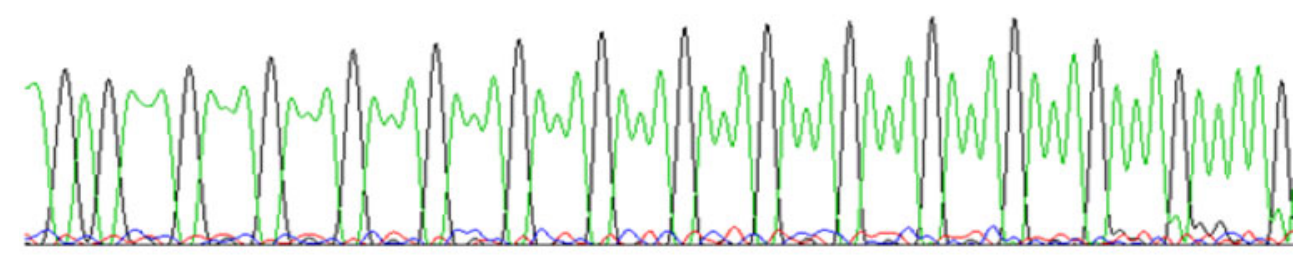

(B)

Cancer: (AAAG),

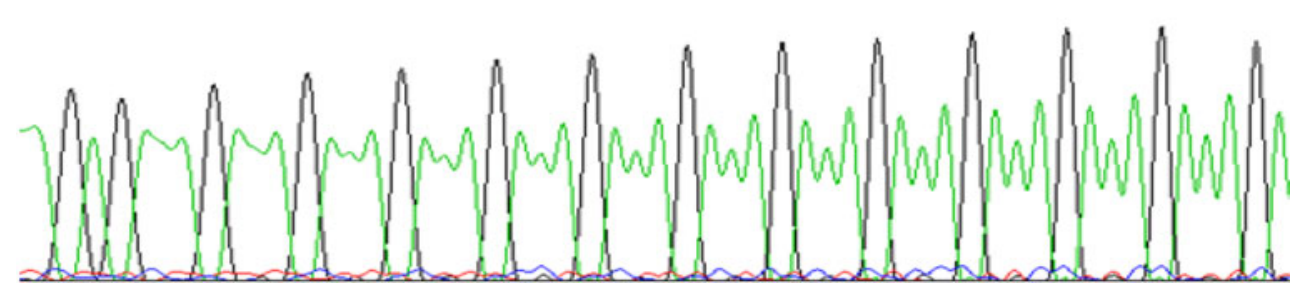

our cohort were associated with a more advanced stage (stage 3 and above) $(18 / 29,62 \%$ vs. $18 / 53,37 \%$ advanced for non-EMAST, $p=0.02$ ). There was no gender association for EMAST tumors (female 20/54, 37\% vs. male 29/87, $33 \%, p=0.717)$.

EMAST Is Correlated with Chronic Inflammation

We assessed all 147 rectal tumors for the pattern and degree of chronic inflammation. Invasive margin, intratumoral, and cancer nests stromal patterns describe inflammatory cells that surround or are at the peripheral edge of the tumor, are within the tumor, or surround the epithelial components of the tumor, respectively. We considered a tumor positive for inflammation if $>50 \%$ of an average of five high-power fields have mononuclear cell infiltrates. With this definition, 54 tumors were positive for chronic inflammation. EMAST tumors were associated with chronic inflammation when compared to non-EMAST tumors (Fig. 2a, Table 4). Although both EMAST and non-EMAST tumors demonstrated an invasive margin or leading edge pattern of inflammation, EMAST tumors showed in addition a predominant amount of chronic inflammation in the stroma surrounding tumor nests (Fig. 2ab, Table 5). Neither EMAST nor non-EMAST tumors demonstrated any intratumoral pattern of inflammatory cell infiltration. The proximity of inflammatory cells to the epithelia components of the tumor might influence EMAST formation.

\section{Discussion}

This study evaluated the prevalence of MSI and EMAST in rectal adenocarcinomas and assessed these with available epidemiological parameters. Rectal cancer, often lumped together with colon cancer, has unique features from colon cancer that include its embryologic origin, its gender differences in incidence, its lower 5-year survivability, its increased local recurrence, and its treatment algorithms. We observed that MSI is rare while EMAST is common among rectal cancers. In this first assessment of clinical parameters with EMAST, EMAST is associated with African-American
Table 2 Frequency of tetranucleotide marker mutations in rectal cancers

\begin{tabular}{lccccc}
\hline Loci & MYCL1 & D20S85 & D8S321 & D20S82 & D9S242 \\
\hline $\begin{array}{l}\text { All rectal tumors } \\
\text { \# Times mutated }(N=147)\end{array}$ & $35(25 \%)$ & $9(8 \%)$ & $43(30 \%)$ & $43(30 \%)$ & $35(24 \%)$ \\
$\begin{array}{l}\text { EMAST tumors } \\
\text { \# Times mutated }(N=49)\end{array}$ & $23(47 \%)$ & $5(10 \%)$ & $30(61 \%)$ & $32(65 \%)$ & $24(49 \%)$ \\
\hline
\end{tabular}


Table 3 MSI and clinicopathological associations among rectal cancers

\begin{tabular}{lllrl}
\hline & MSI-H $(N=3)$ & MSS $(N=144)$ & $p$ value & Total $(N=147)$ \\
\hline \% In cohort population & $2 \%$ & $98 \%$ & NA & $100 \%$ \\
Mean age (SD) & 63.7 & 62.2 & NA & $62(10)$ \\
Gender (M/F) & $3 / 0(100 \% / 0 \%)$ & $84 / 54(61 \% / 39 \%)$ & 0.286 & $87 / 54(62 \% / 38 \%)$ \\
Race (black/white) & $2 / 1(66 \% / 34 \%)$ & $35 / 103(22 \% / 78 \%)$ & 0.168 & $37 / 104(26 \% / 74 \%)$ \\
Stage & & & NA & \\
Local (stages 1 and 2) & - & $46(56 \%)$ & NA & $36(56 \%)$ \\
Regional (stages 3 and 4) & - & $36(44 \%)$ & $54(37.5 \%)$ & $54(37 \%)$ \\
Inflammatory cell infiltration (\%) & - & $54 \%)$ \\
\hline
\end{tabular}

race and more advanced disease. Additionally, in the assessment of chronic inflammation, we found that EMAST was associated with its presence.

The finding shows that only $2 \%$ MSI cases among these rectal cancers is consistent with other studies. ${ }^{15,16}$ MSI has been consistently associated more with right-sided sporadic colon cancer and less with left-sided tumors. ${ }^{2,20-22}$

EMAST has not been previously defined in rectal cancers. Based on our criteria, approximately one third of rectal tumors demonstrate EMAST. This is about half the prevalence reported in the two studies of EMAST in colon cancer. ${ }^{8,23} \mathrm{~A}$ potential reason for this discrepancy is our stringent criteria for at least two tetranucleotide markers positive for its definition, while other studies indicate that one positive tetranucleotide marker can define EMAST. Unlike that for the definition of MSI, there is no consensus on the definition of EMAST in tumors. To date, there is also no consensus tetranucleotide marker panel for EMAST, although most investigators have used similar markers to our study. Yamada et al. have proposed a panel of 10 tetranucleotide in addition to the five loci tested in our study, including L17835, D19S394, L17686, UT5320, and D11S488. ${ }^{23}$ Because of the polymorphic nature of tetranucleotide repeats and the ability of microsatellites to have varying mutation rates based on their sequence context, ${ }^{24}$ we used two or more positive markers to define EMAST. In addition, the majority of the limited studies on EMAST have used two or more tetranucleotide loci instability as criteria for determination of EMAST. To our knowledge, Yamada et al. are the first authors to use one or more tetranucleotide loci instability as criteria for the determination of EMAST.

EMAST is a biomarker for several tumors including endometrial, ovarian, brain, breast, bladder, lung, and softtissue sarcoma. ${ }^{3-7,25-27}$ Several studies could find no link between EMAST and DNA MMR deficiency, the cause of MSI. While the etiology of EMAST is still not clear, general clues point toward some epigenetic relaxation of DNA MMR as one possibility for its cause. It has been shown that (a) colon cancers have heterogeneous expression of the DNA MMR protein MSH3, ${ }^{8}$ suggesting an acquired loss and (b) oxidative stress has been shown to reduce the expression of MSH6 and PMS2, causing faulty DNA MMR that can be corrected when the stress is removed. ${ }^{9,28}$ Additionally, we show in the present study a linkage between EMAST and chronic inflammation, further suggesting that inflammation may fuel the occurrence of EMAST in rectal and possibly other tumors. This hypothesis will need to be tested with appropriate experiments to definitively link EMAST to inflammation. There is a wellestablished association between tumorigenesis and inflammation as suggested in numerous studies. ${ }^{29-31}$ Given this, it would be of great interest to ascertain if the association with

Table 4 EMAST and non-EMAST tumor and clinicopathological associations among rectal cancers

\begin{tabular}{lllll}
\hline & EMAST $(N=49)$ & Non-EMAST $(N=98)$ & $p$ value & Total $(N=147)$ \\
\hline \% In cohort population & $33 \%$ & $67 \%$ & NA & $100 \%$ \\
Mean age (Std dev) & 65.2 & 61.2 & $52(10)$ \\
Gender (M/F) & $29 / 20(60 \% / 40 \%)$ & $58 / 34(63 \% / 37 \%)$ & 0.717 & $87 / 54(62 \% / 38 \%)$ \\
Race (black/white) & $18 / 27(40 \% / 60 \%)$ & $19 / 77(25 \% / 75 \%)$ & 0.014 & $37 / 104(26 \% / 74 \%)$ \\
Stage & $11(38 \%)$ & $35(63 \%)$ & 0.02 & $46(56 \%)$ \\
Local (stages 1 and 2) & $18(62 \%)$ & $18(37 \%)$ & 0.0001 & $36(44 \%)$ \\
Regional/distant (stages 3 and 4) & $30(60 \%)$ & $24(25 \%)$ & $54(37 \%)$ \\
Inflammatory cell infiltration (\%) & & & \\
\hline
\end{tabular}


a

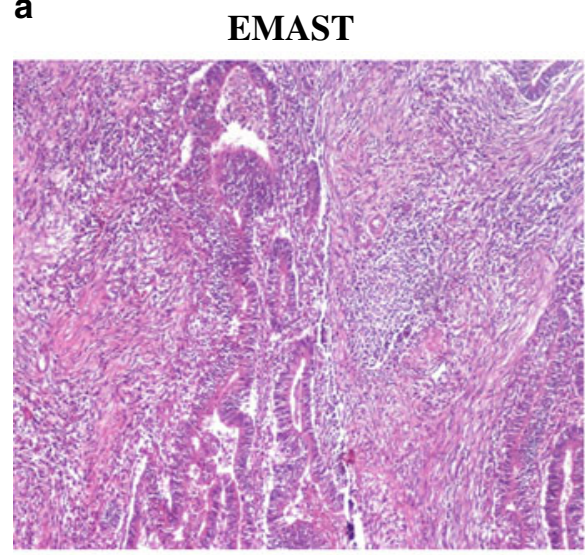

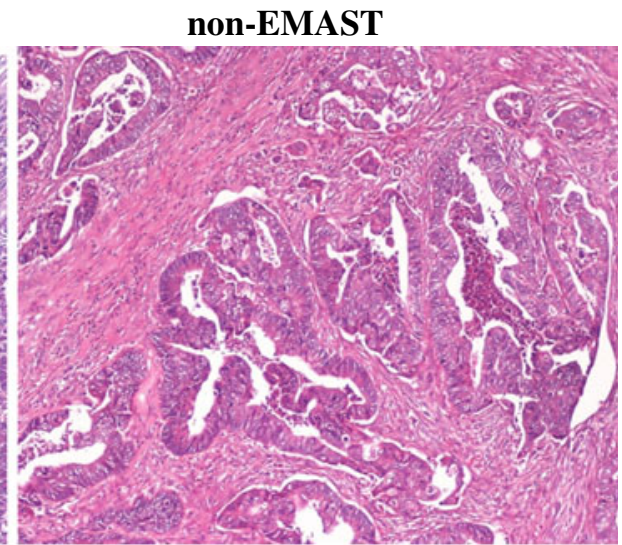

b

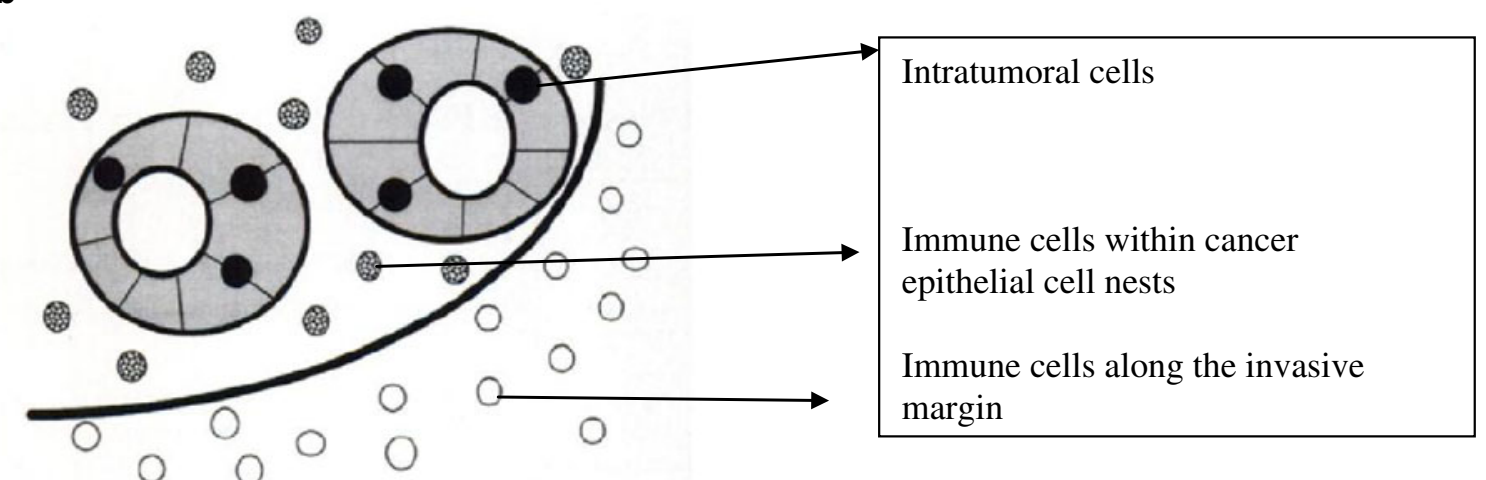

Fig. 2 a Inflammatory cell infiltration in EMAST versus non-EMAST tumor. A significant increase in inflammatory cell infiltrate is observed in the stroma of EMAST tumors compared to non-EMAST tumors. b Pattern of inflammatory cell infiltration. The vast majority of EMAST

inflammation demonstrated here with EMAST does also lead to tumorigenesis, either primarily through downregulation of specific mismatch repair genes as shown previously in our lab ${ }^{9}$ or secondarily via frameshift mutations of specific genes containing such tetranucleotide repeats in their sequences. It is our hope that this preliminary study demonstrating the high prevalence of EMAST would foster increased research that might help clarify the biological significance of EMAST.

In our study, EMAST was associated with more advanced disease compared to non-EMAST tumors. We also noted a higher incidence of EMAST among rectal tumors from African Americans compared to Caucasians. This observation suggests the possibility that EMAST might be predictive of a reduced survival compared to tumors demonstrated inflammation within the cancer cell nests and along the invasive margin. Inflammation in non-EMAST tumors had a much lower incidence and occurred only along the invasive margin. Adapted from Naito et al. ${ }^{19}$

non-EMAST tumors, although this has not been evaluated. In contrast to our results, Yamada et al. did not find any significant correlation between EMAST and disease stage. ${ }^{23}$ One possible reason that could account for the observed differences between the two studies is the varying ethnicity in each study (Caucasians and African Americans vs. Japanese) that makes up our respective cohorts.

In summary, among our rectal cancer cohort, we rarely found MSI but EMAST has a common prevalence. EMAST in rectal tumors was associated with tumors from African Americans and with patients with advanced stage. EMAST was also associated with the presence of chronic inflammatory cells. We suggest that EMAST may confer a poorer prognosis among rectal cancer patients, and its etiology is caused by inflammation.
Table 5 Lymphocyte infiltration patterns in EMAST and non-EMAST rectal tumors

\begin{tabular}{lcccc}
\hline & EMAST $(N=49)$ & Non-EMAST $(98)$ & $p$ value & Total \\
\hline Lymphocyte infiltration & $30(60 \%)$ & $24(25 \%)$ & 0.0001 & 54 \\
Stromal nests & $24(83 \%)$ & $4(17 \%)$ & $<0.0001$ & 28 \\
Margin & $30(100 \%)$ & $24(100 \%)$ & NA & 54 \\
\hline
\end{tabular}


Acknowledgements Supported by the US Public Health Service (DK067287 to JMC), the UCSD Digestive Diseases Research Development Center (DK080506), and the San Diego State University/UCSD Comprehensive Cancer Center Partnership (CA132379 and CA13238).

Disclosure All authors declare no conflict or competing interest for this manuscript.

Open Access This article is distributed under the terms of the Creative Commons Attribution Noncommercial License which permits any noncommercial use, distribution, and reproduction in any medium, provided the original author(s) and source are credited.

\section{References}

1. Boland CR, Thibodeau SN, Hamilton SR, Sidransky D, Eshleman JR, Burt RW, Meltzer SJ, Rodriguez-Bigas MA, Fodde R, Ranzani GN, Srivastava S. A National Cancer Institute Workshop on Microsatellite Instability for cancer detection and familial predisposition: development of international criteria for the determination of microsatellite instability in colorectal cancer. Cancer Res. 1998;58:5248-57.

2. Grady WM and Carethers JM. Genomic and epigenetic instability in colorectal cancer pathogenesis. Gastroenterology 2008;135:10791099.

3. Ahrendt SA, Chow JT, Xu LH et al. Molecular detection of tumor cells in bronchoalveolar lavage fluid from patients with early stage lung cancer. J Natl Cancer Inst 1999;91:332-9.

4. Xu L, Chow J, Bonacum $\mathrm{J}$ et al. Microsatellite instability at AAAG repeat sequences in respiratory tract cancers. Intl J Cancer 2001;91:200-4.

5. Danaee H, Nelson HH, Karagas MR et al. Microsatellite instability at tetranucleotide repeats in skin and bladder cancer. Oncogene 2002;21:4894-9.

6. Singer G, Kallinowski T, Hartmann A et al. Different types of microsatellite instability in ovarian carcinoma. Intl $\mathrm{J}$ Cancer 2004;112:643-6.

7. Catto JW, Azzouzi AR, Amira $\mathrm{N}$ et al. Distinct patterns of microsatellite instability are seen in tumors of the urinary tract. Oncogene 2003;22:8699-706.

8. Haugen AC, Goel A, Yamada K, Boland CR et al. Genetic instability caused by loss of MutS homologue 3 in human colorectal cancer. Cancer Res. 2008;68:8465-8472.

9. Chang CL, Marra G, Carethers JM et al. Oxidative stress inactivates the human DNA mismatch repair system. Am J Physiol Cell Physiol 2002;283:C148-154.

10. Julien LA, Thorsen AG. Current neoadjuvant strategies in rectal cancer. J Surg Oncol. 2010 Mar 15; 101(4):321-6

11. Park J, Neuman HB, Wong WD et al. Randomized control trials in rectal and anal cancer. Surg Oncol Clin N Am. 2010 Jan; 19(1):205-23

12. Berardi $\mathrm{R}$, Cascinnus $\mathrm{S}$ et al. Locally advanced rectal cancer: from molecular profiling to clinical practice. A literature review. Exp Opin Pharmacother. 2009 Oct; 10(15):2467-78

13. Kuremsky JG, McLeod HL et al. Biomarkers for response to neoadjuvant chemoradiation for rectal cancer. Int J Radiat Oncol Biol Phys. 2009 Jul 1; 74(3):673-88

14. Choi MY, Chung DC et al. Microsatellite instability is frequently observed in rectal cancer and is influenced by neoadjuvant chemoradiation. Int J Radiat Oncol Biol Phys. 2007 Aug 1; 68(5):1584

15. Kalady MF, Sanchez JA, Manilich E, Hammel J, Casey G, Church JM. Divergent oncogenic changes influence survival differences between colon and rectal adenocarcinomas. Dis Colon Rectum. 2009 Jun;52(6):1039-45.
16. Slattery ML, Curtin K, Wolff RK, Boucher KM, Sweeney C, Edwards S, Caan BJ, Samowitz W. A comparison of colon and rectal somatic DNA alterations. Dis Colon Rectum. 2009 Jul;52(7):1304-11.

17. Samowitz et al. Microsatellite instability and survival in rectal cancer. Cancer Causes Control. 2009 Nov;20(9):1763-8.

18. Satia JA, Keku T, Galanko JA, Martin C, Doctolero RT, Tajima A, Sandler RS, Carethers JM. Diet, lifestyle, and genomic instability in the North Carolina Colon Cancer Study. Cancer Epidemiol Biomarkers Prev, 14:429-436, 2005.

19. Naito $\mathrm{Y}$ et al. CD8+ T cells infiltrated within cancer cell nests as a prognostic factor in human colorectal cancer. Cancer Res 1998;58:3491-4

20. Huang S, Lee JK, Smith EJ, Doctolero RT, Tajima A, Beck SE, Weidner N, Carethers JM. Evidence for an hMSH3 defect in familial hamartomatous polyps. Cancer 2010 (in press).

21. Urso E, Pucciarelli S, Agostini M, Maretto I, Mescoli C, Bertorelle R, Viel A, Rugge M, Nitti D. Proximal colon cancer in patients aged 51-60 years of age should be tested for microsatellites instability. A comment on the Revised Bethesda Guidelines. Int J Colorectal Dis. 2008 Aug;23(8):801-6.

22. Cho YK, Kim HC, Kim SH, Park JH, Yun HR, Cho YB, Yun SH, Lee WY, Chun HK. Location-related differences in sporadic microsatellite unstable colorectal cancer. Dig Liver Dis. 2010;42:611-615

23. Yamada K, Kanazawa S, Koike J, Sugiyama H, Xu C, Funahashi K, Boland CR, Koi M, Hemmi H. Microsatellite instability at tetranucleotide repeats in sporadic colorectal cancer in Japan. Oncol Rep. 2010 Feb;23(2):551-61.

24. Chung H, Lopez CG, Holmstrom J, Young DJ, Lai JF, ReamRobinson D, Carethers JM. Both microsatellite length and sequence context determine frameshift mutation rates in defective DNA mismatch repair. Hum Mol Genet. 2010 Apr; 19:2638-2647

25. Yoo Duk Choi, Jin Choi, Jo Heon Kim et al. Microsatellite instability at a tetranucleotide repeat in type I endometrial carcinoma. J Exp Clin Cancer Res. 2008; 27(1): 88

26. Wooster R, Cleton-Jansen AM, Collins N, Mangion J, Cornelis RS, Cooper CS, Gusterson BA, Ponder BA, von Deimling A, Wiestler OD. Instability of short tandem repeats (microsatellites) in human cancers. Nat Genet. 1994;6:152-6. doi:10.1038/ng0294-152.

27. Ahrendt SA, Decker PA, Doffek K, Wang B, Xu L, Demeure MJ, Jen J, Sidransky D. Microsatellite instability at selected tetranucleotide repeats is associated with p53 mutations in non-small cell lung cancer. Cancer Res. 2000 May 1;60(9):2488-91.

28. Edwards RA, Witherspoon M, Wang K, Afrasiabi K, Pham T, Birnbaumer L, Lipkin SM. Epigenetic repression of DNA mismatch repair by inflammation and hypoxia in inflammatory bowel disease-associated colorectal cancer. Cancer Res. 2009 Aug 15;69(16):6423-9.

29. Terzić J, Grivennikov S, Karin E, Karin M. Inflammation and colon cancer. Gastroenterology. 2010 Jun;138(6):2101-2114.e5

30. Erdman SE, Poutahidis T. Roles for inflammation and regulatory T cells in colon cancer. Toxicol Pathol. 2010;38(1):76-87.

31. Wang S, Liu Z, Wang L, Zhang X. NF-kappaB signaling pathway, inflammation and colorectal cancer. Cell Mol Immunol. 2009 Oct;6 (5):327-34.

\section{Discussant}

Dr. David Shibata (Tampa, FL): I would like to congratulate the authors on a very interesting paper and particularly to give us a greater awareness of what may be a new subset of mismatch repair deficient colorectal cancer. 
One of my major questions about your study is with respect to the actual patients that were included in this study. There are a fair amount of locally advanced rectal cancers here. So my question is, were any of your tissues pretreated with chemotherapy and/or radiation?

\section{Closing discussant}

Dr. Bikash Devaraj: Most of the stage II and above cancer patients were treated with preoperative chemo XRT. We did a subanalysis trying to determine just that, and we found that there was no relation between advanced stage and inflammation at this point.

\section{Discussant}

Dr. David Shibata (Tampa, FL): I think it's interesting, and this brings up an important point, that MSH3 is a very quirky mismatch repair gene and, in fact, it's very heterogenous in terms of its expression, even between individual tumor cells. In fact, it may be - as you statedthat the expression is impacted by cellular stress. So I would be very curious to see, and I think it would be interesting for your study, to do MSH-3 immunohistochemistry on your specimens, and particularly for those patients that were treated with radiation. It would be very interesting to see what the correlation would be between EMAST and MSH3 in those tissues.

The other question then is, given that this seems to be a state-based registry, why is there such a lack of data on tumor stage on almost half of the patients?

\section{Closing discussant}

Dr. Bikash Devaraj: I don't have a good answer to that question at this point.

\section{Discussant}

Dr. David Shibata (Tampa, FL): Because I think in terms of making a statement on prognosis and stage, to have half of your patients not having stage data, I think if you can try to get that, I think that would strengthen things, certainly.

\section{Closing discussant}

Dr. Bikash Devaraj: But, again, if you look at the overall correlation and as you know, about half of them are not there, them we did not have stage data for-it's about equivalent in terms of the stage that we have for EMAST tumors versus non-EMAST tumors. Thus, so I still think you can draw a correlation between the two.

\section{Discussant}

Dr. David Shibata (Tampa, FL): And finally, I think the other studies that you had cited invariably show that MSIhigh tumors were all EMAST positive. And I'm just wondering whether you did genetic testing on these patients. Were they HNPCC perhaps and not just sporadic MLH1 deficient tumors?

\section{Closing discussant}

Dr. Bisash Devaraj: As far as we know, none of these patients were HNPCC patients. And you are correct, the majority of the papers out there do show that EMAST tumors tend to be MSI-high tumors, too. But again, we had such low numbers of traditional MSI-high tumors that this may be one of the reasons why we did not see that correlation.

\section{Discussant}

Dr. David Shibata (Tampa, FL): Did you categorize any as MSI-low?

\section{Closing discussant}

Dr. Bikash Devaraj: No, we did not. 